DELEITO, C.S.R.; CARMO, M.G.F.; FERNANDES, M.C.A.; ABBOUD, A.C.S. Ação bacteriostática do biofertilizante Agrobio in vitro. Horticultura Brasileira, Brasília, v.23, n.2, p.281-284, abr-jun 2005.

\title{
Ação bacteriostática do biofertilizante Agrobio in vitro ${ }^{1}$
}

\author{
Cláudia S.R. Deleito ${ }^{2 *}$; Margarida Goréte F. do Carmo ${ }^{2 b}$; Maria do Carmo de A. Fernandes ${ }^{3}$; Antonio \\ Carlos de S. Abboud ${ }^{2}$
}

${ }^{2}$ UFRRJ-Depto. Fitotecnia; ${ }^{3}$ PESAGRO-RIO, EE de Seropédica, 23.851-970 Seropédica-RJ; *Aluna do curso de Pós-graduação em Fitotecnia; E-mail: csayaord@ufrrj.br; gorete@ufrrj.br

\section{RESUMO}

Agrobio é um biofertilizante produzido a partir de esterco bovino fresco, água, melaço e sais minerais, submetidos à fermentação em temperatura ambiente por aproximadamente 56 dias em recipientes abertos. Este produto, desenvolvido pela PESAGRO-RIO (EES) tem sido largamente utilizado por agricultores orgânicos e convencionais no estado do Rio de Janeiro, ao qual atribuem efeito nutricional e de controle de doenças em diferentes culturas. No presente trabalho avaliou-se o efeito de antibiose e de concentrações do Agrobio contra Xanthomonas euvesicatoria, in vitro. Realizaram-se quatro bioensaios, utilizando-se três isolados distintos da fitobactéria, e compararam-se amostras de Agrobio em diferentes estágios de preparação ( $35 ; 85$ e 115 dias) e submetidos a três tratamentos (autoclavado a $120^{\circ} \mathrm{C} / 20 \mathrm{~min}$; filtrado $0,22 \mu \mathrm{m}$; original). Utilizouse o método de escavação em placa e o efeito dos tratamentos foi medido pelo diâmetro do halo de inibição formado. Constatou-se que Agrobio apresenta ação bacteriostática sobre X. euvesicatoria, independente da idade da amostra e do tratamento aplicado ao produto, e inibição do crescimento do patógeno à concentração acima de $5 \%$, o que sugere a viabilidade de se utilizar este biofertilizante, a partir de 35 dias de fermentação, como medida auxiliar no controle da mancha-bacteriana do pimentão, necessitando porém, de confirmações por meios de estudos em condições de campo.

Palavras-chave: Capsicum annuum L., Xanthomonas euvesicatoria, antibiose.

\begin{abstract}
Bacteriostatic action of biofertilizer Agrobio in vitro

Agrobio is a biofertilizer prepared from fresh cattle manure, water, molasses and minerals, fermented under room temperature in open containers during 56 days. This product has been widely used by organic and conventional farmers throughout Rio de Janeiro State, Brazil, to control several plant pathogens of various crops. The antibiotic effect of different concentrations of Agrobio against Xanthomonas euvesicatoria, in vitro vas evaluated. Four bioassays were performed with three isolates of the bacterium. Agrobio was tested in three preparation stages $(35,85$ and 115 days of fermentation) and applied raw, filtered $(0,22 \mu \mathrm{m})$ or autoclaved $\left(120^{\circ} \mathrm{C} / 20\right.$ minutes). The effect of the treatments was assessed by the diameter of the inhibition growth halo on Petri dishes. Agrobio presented bacteriostatic effect on X. euvesicatoria regardless of the sample age or pre-treatment. Growth inhibition occurred above 5\% concentration, indicating the feasibility of Agrobio, as a bacterial leaf spot control agent, in early fermentation stages ( 35 days). Field experiments are necessary to confirm these results.
\end{abstract}

Keywords: Capsicum annuum L., Xanthomonas euvesicatoria, antibiosis.

(Recebido para publicação em 1 de abril de 2004 e aceito em 8 de março de 2005)

$\mathrm{N}^{\circ}$ o estado do Rio de Janeiro, um dos biofertilizantes mais conhecidos e utilizados em várias culturas é o Agrobio, produzido e pesquisado na EE de Seropédica da PESAGRO- RIO. O Agrobio é obtido por meio da transformação microbiana, em sistema aberto, de uma mistura de água, esterco bovino fresco, melaço, leite e sais minerais. Após cerca de 56 dias, dependendo das condições ambientais, o produto pode ser engarrafado para uso em lavouras, como fertilizante foliar e também para controlar algumas doenças em mudas de hortaliças folhosas, de ornamentais e de fruteiras em geral (FERNANDES, 2000). Porém, apesar do uso freqüente de biofertilizantes em diferentes culturas, seja como adubo foliar ou como auxiliar no controle de pragas e doenças, o seu modo de ação não é conhecido, apesar de resultados práticos satisfatórios (BETTIOL et al, 1997).

No Agrobio há uma comunidade microbiana composta por fungos (Fusarium tabacinum), bactérias (Lactobacillus spp. e Bacillus subtilis) leveduras (Candida spp. e, principalmente, Cryptococcus laurentii) e actinomicetos (Streptomyces spp.) (DELEITO, 2002) e acredita-se que a sua ação possa estar relacionada ao aumento da atividade microbiana propiciada pelas aplicações freqüentes do produto.
Não existem informações na literatura do efeito do Agrobio sobre o desenvolvimento de fitopatógenos, porém já existem relatos para outros biofertilizantes. Castro et al. (1991) comprovaram o efeito do biofertilizante proveniente da digestão anaeróbia do esterco bovino causando inibição do crescimento de Colletotrichum gloeosporioides, agente da antracnose do maracujá, de Thielaviopsis paradoxa, agente da podridão do abacaxi, de Penicillium digitatum agente do mofo verde dos citrus e de Cladosporium sp., agente da mancha deprimida do maracujá. Tratch e Bettiol (1997) verificaram em biofertilizante produzido com a

${ }^{1}$ Parte da Dissertação de Mestrado apresentada pela primeira autora ao Curso de Pós-Graduação em Fitotecnia da UFRRJ; bolsista da CAPES. 
Tabela 1. Inibição do crescimento de Xanthomonas euvesicatoria (ENA 4170) in vitro, por diferentes tratamentos, expresso pelo diâmetro do halo de inibição formado ( $\mathrm{mm})$. Seropédica, UFRRJ, 2001

\begin{tabular}{lrc}
\hline Tratamento & Halo (mm) \\
\hline Sulfato de estreptomicina $(0,24 \mathrm{mg} / \mathrm{ml})$ & 17,16 a \\
Sulfato de cobre $(0,24 \mathrm{mg} / \mathrm{ml})$ & 12,66 ab \\
Agrobio com 115 dias filtrado $(0,22 \mu \mathrm{m})(5 \%)$ & 8,44 bc \\
Agrobio com 85 dias autoclavado $\left(120_{\circ} \mathrm{C} / 20 \mathrm{~min}\right)(5 \%)$ & 8,27 & $\mathrm{c}$ \\
Agrobio com 115 dias autoclavado $\left(120_{\circ} \mathrm{C} / 20 \mathrm{~min}\right)(5 \%)$ & 8,22 & $\mathrm{c}$ \\
Agrobio com 85 dias filtrado $(0,22 \mu \mathrm{m})(5 \%)$ & 7,94 & $\mathrm{C}$ \\
Agrobio com 35 dias filtrado $(0,22 \mu \mathrm{m})(5 \%)$ & 7,72 & $\mathrm{c}$ \\
Agrobio com 35 dias autoclavado $(120, \mathrm{C} / 20 \mathrm{~min})(5 \%)$ & 7,38 & $\mathrm{c}$ \\
Agrobio com 85 dias original $(5 \%)$ & 6,83 & $\mathrm{c}$ \\
Agrobio com 115 dias original $(5 \%)$ & 6,33 & $\mathrm{c}$ \\
Agrobio com 35 dias original $(5 \%)$ & 5,72 & $\mathrm{c}$ \\
Água & 0,0 & $\mathrm{~d}$ \\
\hline CV $\%$ & 25,0 & \\
\hline
\end{tabular}

* Médias seguidas da mesma letra não diferem estatisticamente pelo teste de Tukey a 5\%.

adição de sais e resíduos orgânicos, que concentrações acima de $15 \%$ inibiram completamente o crescimento micelial de Alternaria solani, Stemphylium solani, Septoria lycopersici, Sclerotinia sclerotiorum, Botrytis cinerea, Rhizoctonia solani e Fusarium oxysporum f. sp. phaseoli e a germinação de esporos de B. cinerea, A. solani, Hemileia vastatrix e Coleosporium plumierae.

Não existem, porém, relatos do efeito de biofertilizantes sobre bactérias fitopatogênicas, em geral de difícil controle no campo, e para as quais existem apenas duas opções de controle químico, antibióticos ou fungicidas à base de cobre. É o que ocorre com a manchabacterina do pimentão, causada por Xanthomonas axonopodis pv. vesicatoria, renomeada por Jones et al. (2004) como Xanthomonas euvesicatoria. No campo, após início da epidemia, normalmente é recomendada a aplicação de fungicidas cúpricos ou cuprorgânicos que, em geral, não diferem entre si (MARCO; STALL, 1983; AGUIAR et al, 2003) exceto quando da ocorrência de estirpes resistentes ao cobre, onde o segundo pode apresentar maior eficiência (MARCO; STALL, 1983) ou não (JONES et al., 1991; AGUIAR et al, 2003). Aguiar et al. (2000) relatam a ocorrência no Brasil de estirpes resistentes a até $1800 \mu \mathrm{l} / \mathrm{ml}$ de cobre. O controle químico é ainda dificultado pela ocorrência alta e frequiente de estirpes resistentes ao sulfato de estreptomicina (JONES et al., 1991; WARD; O'GARRO, 1992; QUEZADO-DUVAL et al., 2003).

Tendo em vista a necessidade de se desenvolverem novas tecnologias para o manejo de fitobacterioses o presente trabalho foi realizado para avaliar o efeito de antibiose do Agrobio contra Xanthomonas euvesicatoria, in vitro.

\section{MATERIAL E MÉTODOS}

Para testar o efeito de antibiose do biofertilizante Agrobio foram feitos quatro bioensaios, in vitro, com três isolados da fitobactéria (ENA 4170, ENA 4370 e ENA 818) utilizando-se o método de escavação em placa (SALGADO et al., 2002). Em placas de Petri de 20 $\mathrm{cm}$ de diâmetro contendo $50 \mathrm{ml}$ de meio Nutriente Agar (FAHY; HAYWARD, 1983) foram distribuídos $0,5 \mathrm{ml}$ de suspensão bacteriana em solução salina $(\mathrm{NaCl}$ a $0,85 \%)$ ajustada em espectrofotômetro para $75 \%$ de transmitância, a $600 \mathrm{~nm}\left(10^{8} \mathrm{ufc} / \mathrm{ml}\right)$. Após secagem do líquido excedente foram feitos seis orifícios de $5 \mathrm{~mm}$ de diâmetro aos quais foram adicionados $25 \mu \mathrm{l}$ de amostras dos respectivos tratamentos. A leitura dos resultados foi feita após 48 horas de incubação a $28^{\circ} \mathrm{C}$, medindo-se o halo de inibição formado. Utilizou-se o delineamento inteiramente ao acaso, com cinco repetições representadas por uma placa ou seis orifícios cada.
No primeiro bioensaio, utilizou-se o isolado ENA 4170 e o biofertilizante Agrobio a 5\% com 35 dias de preparo, 85 e 115 dias (prontos para uso), e submetidos aos tratamentos: original, filtrados em milipore $(0,22 \mu \mathrm{m})$ e autoclavados $\left(120^{\circ} \mathrm{C} / 20\right.$ minutos $)$. Como controles, utilizaram-se os tratamentos adicionais: sulfato de cobre $(0,24 \mathrm{mg} / \mathrm{ml})$ e sulfato de estreptomicina $(0,24 \mathrm{mg} / \mathrm{ml})$ e água. A concentração dos respectivos bactericidas foi escolhida com base em testes in vitro visando a obtenção de halos homogêneos e com diâmetro maior que $12 \mathrm{~mm}$ conforme Salgado (2002), independente das concentrações recomendadas para produtos comerciais em condições de campo. No segundo bioensaio, utilizou-se o isolado ENA 4370 e comparou-se o Agrobio, com os três períodos de preparo e as três preparações, citados anteriormente, arranjados em esquema fatorial $(3 \times 3)$. Como controle, utilizou-se o diluente água destilada e autoclavada. No terceiro bioensaio, utilizou-se o isolado ENA 818 e compararam-se os tratamentos: Agrobio a 5\%, pronto para uso (56 dias), em sua forma original, filtrado em milipore e autoclavado e três testemunhas, água, sulfato de cobre $(0,24 \mathrm{mg} /$ $\mathrm{ml})$ e sulfato de estreptomicina $(0,24$ $\mathrm{mg} / \mathrm{ml}$ ). Os resultados dos bioensaios foram submetidos à análise de variância e ao teste de Tukey a 5\% de probabilidade.

A fim de se estabelecer uma relação entre os princípios ativos usuais, cobre e antibiótico, e o Agrobio, testou-se no quarto bioensaio a resposta do patógeno (isolado ENA 818) a doses crescentes do Agrobio (0; 2,5; 5; 7,5; 10; 20; 25; $30 ; 40$ e $50 \mathrm{ml} / 100 \mathrm{ml}$ ) e como testemunha utilizaram-se também doses crescentes de sulfato de cobre $(0 ; 0,2 ; 0,3$; 0,$4 ; 0,5 ; 1,0 ; 2,0 ; 3,0 ; 4,0$ e 5,0 g/100 $\mathrm{ml})$ e de sulfato de estreptomicina $(0$; 0,0001; 0,0005; 0,001; 0,005; 0,01; 0,05; $0,1 ; 0,5$ e $1,0 \mathrm{~g} / 100 \mathrm{ml})$. Com as médias dos halos, obtidas em três repetições, representadas por três placas com seis orifícios, foram construídos gráficos em função das doses dos três produtos.

\section{RESULTADOS E DISCUSSÃO}

O biofertilizante Agrobio apresentou ação bacteriostática sobre $X$. euvesicatoria para os três isolados tes- 
tados, independente do tempo de preparo e do tratamento aplicado ao produto, confirmado pela inibição do crescimento bacteriano na região dos halos, porém permitindo a recuperação da fitobactéria por meio de repicagens a partir da referida região.

No primeiro bioensaio, realizado com isolado ENA 4170, o Agrobio, independente do tempo de preparo e do tratamento aplicado ao mesmo, apresentou atividade bacteriostática, com halo de inibição variando de 5,72 a 8,44 mm, que não diferiram estatisticamente entre si, que por sua vez foram superiores à testemunha água $(0,0 \mathrm{~mm})$ e inferiores ao sulfato de cobre $(12,7 \mathrm{~mm})$ e ao sulfato de estreptomicina $(17,2 \mathrm{~mm})$ (Tabela 1). Este resultado foi confirmado no segundo bioensaio, realizado com o isolado ENA 4370, onde não foi observada interação significativa entre o período de preparo e a preparação do biofertilizante (filtragem, autoclavagem e amostra original), nem diferenças significativas entre os tratamentos. Observou-se nos tratamentos com Agrobio halo médio de $8,7 \mathrm{~mm}$ enquanto que no diluente, água, este foi de $0,0 \mathrm{~mm}$.

Já no terceiro bioensaio, realizado com o isolado ENA 818 e amostras de Agrobio com 56 dias de preparo, observou-se maior diâmetro dos halos de inibição em relação àqueles observados para os isolados ENA 4170 e ENA 4370 (Tabela 2). Os halos de inibição nos tratamentos com o biofertilizante original $(13,3 \mathrm{~mm})$ e filtrado $(13,2 \mathrm{~mm})$ e o sulfato de cobre $(12,3 \mathrm{~mm})$ não diferiram estatisticamente, mas por sua vez foram superiores estatisticamente aos halos formados no produto autoclavado (10,4 $\mathrm{mm})$ e à água $(0,0 \mathrm{~mm})$, sendo todos, porém, significativamente inferiores ao sulfato de estreptomicina $(31,8 \mathrm{~mm})$. Embora não existam relatos na literatura sobre o efeito de biofertilizantes sobre a fitobactéria em estudo, o presente resultado confirmam os de Castro et al. (1991) e os de Tratch e Bettiol (1997) que observaram atividade antimicrobiana de dois diferentes biofertilizantes, caracterizada pela inibição da germinação de conídios e do crescimento micelial de diferentes fungos.

A filtragem e a autoclavagem não reduziram o tamanho do halo de inibi-

Tabela 2. Inibição do crescimento de Xanthomonas euvesicatoria (ENA 818) in vitro por diferentes tratamentos, expresso pelo diâmetro do halo de inibição formado (mm). Seropédica, UFRRJ, 2001.

\begin{tabular}{lc}
\hline Tratamento & Halo $(\mathrm{mm})$ \\
\hline Sulfato de estreptomicina $(0,24 \mathrm{mg} / \mathrm{ml})$ & $31,80 \mathrm{a}$ \\
Sulfato de cobre $(0,24 \mathrm{mg} / \mathrm{ml})$ & $12,30 \mathrm{~b}$ \\
Agrobio com 56 dias original $(5 \%)$ & $13,30 \mathrm{~b}$ \\
Agrobio com 56 dias filtrado $(0,22 \mu \mathrm{m})(5 \%)$ & $13,20 \mathrm{~b}$ \\
Agrobio com 56 dias autoclavado $(120 \mathrm{O} / 20 \mathrm{~min})(5 \%)$ & $10,40 \mathrm{c}$ \\
Água & $0,00 \mathrm{~d}$ \\
\hline CV \% & 7,39 \\
\hline
\end{tabular}

* Médias seguidas da mesma letra não diferem estatisticamente pelo teste de Tukey a 5\%.
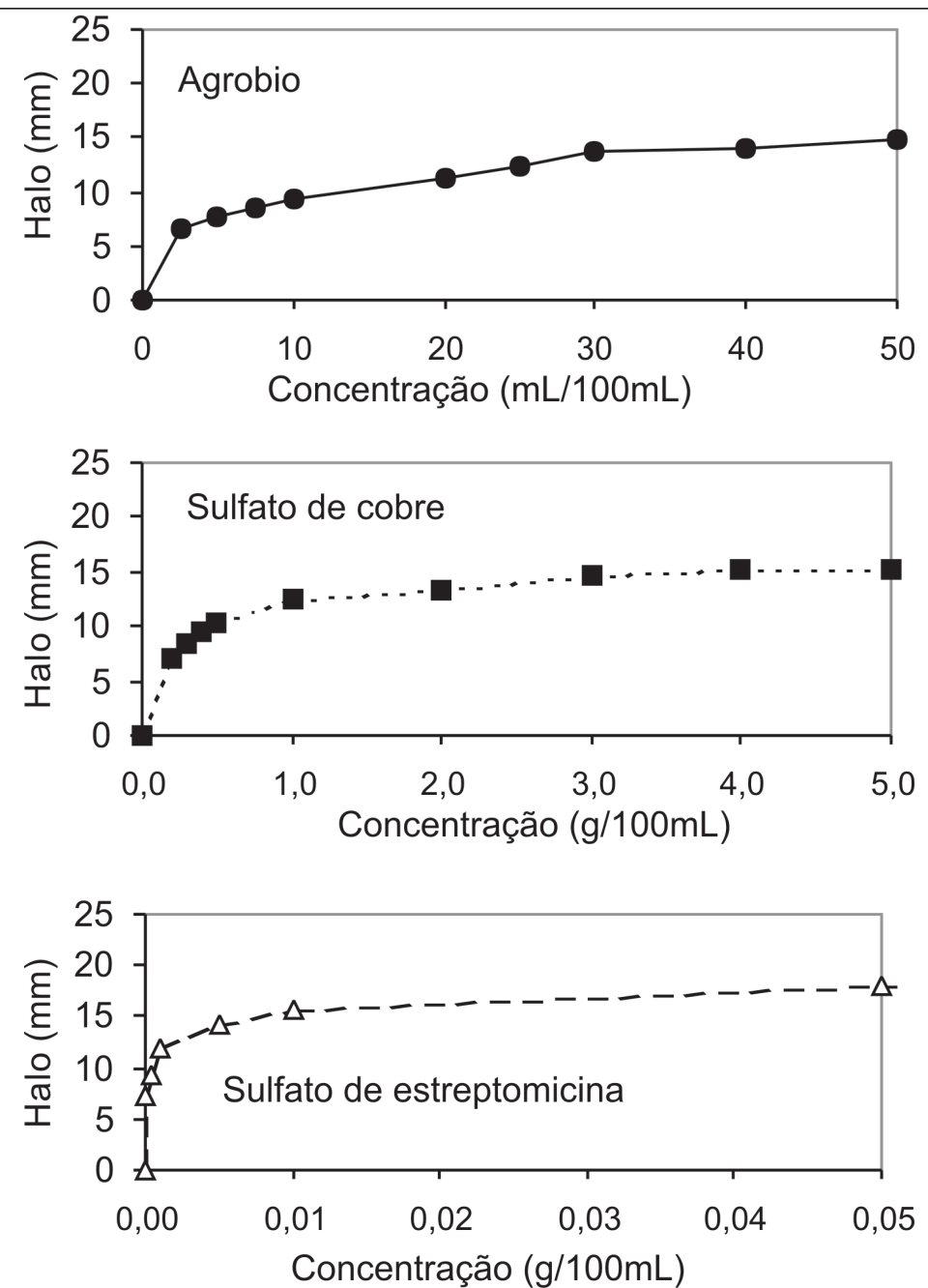

Figura 1. Halo de inibição $(\mathrm{mm})$ do crescimento de Xanthomonas euvesicatoria, in vitro, promovido por doses crescentes do biofertilizante Agrobio $(\mathrm{ml} / 100 \mathrm{ml})$, sulfato de cobre $(\mathrm{g} /$ $100 \mathrm{ml})$ e sulfato de estreptomicina $(\mathrm{g} / 100 \mathrm{ml})$. Seropédica, UFRRJ, 2001.

ção o que sugere que a ação do produto deve-se à presença de substâncias bacteriostáticas no mesmo e não somente à ação direta da flora microbiana e, que essas substâncias estão presentes no produto independente do período de pre- paro (36 a 100 dias), não sendo termolábeis, concordando com os resultados de Tratch e Bettiol (1997). A ação bacteriostática in vitro, confirmada no presente ensaio, pode estar associada à presença de Bacillus subtilis em todas 
as fases do preparo do Agrobio (Deleito, 2002), que é reconhecidamente um produtor de antibiótico (BETTIOL e KIMATI, 1990; CASTRO et al., 1991). São necessários, porém, estudos em condições de campo para comprovação deste efeito no filoplano.

No quarto ensaio, em que se avaliou o efeito de concentrações crescentes do Agrobio comparado a doses crescentes de sulfato de estreptomicina e de sulfato de cobre em relação ao patógeno (isolado ENA 818), observou-se aumento do diâmetro dos halos de inibição com o aumento da concentração de Agrobio. No Agrobio, observou-se halo médio de 9,0 mm à concentração de $10 \mathrm{ml} / 100 \mathrm{ml}$, e de 15 mm à concentração de 50 ml/100 $\mathrm{ml}$, enquanto que para do sulfato de cobre registraram-se halos de $13 \mathrm{~mm}$ e 15 $\mathrm{mm}$ às concentrações de $1,0 \mathrm{~g} / 100 \mathrm{ml} \mathrm{e}$ $5,0 \mathrm{~g} / 100 \mathrm{ml}$, respectivamente, e para sulfato de estreptomicina halos de $12 \mathrm{~mm}$ e $18 \mathrm{~mm}$ às concentrações de $0,001 \mathrm{~g} /$ $100 \mathrm{ml} \mathrm{e} \mathrm{0,05} \mathrm{g/100} \mathrm{ml} \mathrm{(Figura} \mathrm{1).}$

Estes resultados mostram atividade de antibiose do Agrobio, porém, muito menos acentuada que a do antibiótico sulfato de estreptomicina e do cobre e, sugerem a viabilidade de se utilizar o biofertilizante Agrobio, após 35 dias de fermentação como medida auxiliar no controle da mancha-bacteriana do pimentão, confirmando os resultados de Deleito (2002) em ensaios em condições de casa-de-vegetação. São necessários, porém, confirmações deste efeito por meio de estudos epidemiológicos em condições de campo, tendo em vista a complexidade do controle químico desta fitobacteriose (MARCO; STALL, 1983; JONES et al., 1991; AGUIAR et al., 2000; CARMO et al., 2001; AGUIAR et al., 2003).

\section{AGRADECIMENTOS}

À CAPES pela concessão da bolsa de mestrado à primeira autora, ao CNPq e à FAPERJ pelo financiamento do projeto.

\section{LITERATURA CITADA}

AGUIAR, L.A.; KIMURA, O.; CASTILHO, A.M.C.; CASTILHO, K.S.C.; RIBEIRO, R.L.D.; AKIBA, F.; CARMO, M.G.F. Efeito de formulações cúpricas e cuprorgânicas na severidade da mancha-bacteriana e na população residente de Xanthomonas campestris pv. vesicatoria em pimentão. Horticultura Brasileira, Brasília, v.21, n.1, p.44-50, 2003.

AGUIAR, L.A.; KIMURA, O.; CASTILHO, A.M.C.; CASTILHO, K.S.C.; RIBEIRO, R.L.D.; AKIBA, F.; CARMO, M.G.F. Resistência ao cobre em isolados nacionais de Xanthomonas campestris pv. vesicatoria de pimentão e tomateiro. Agronomia, v.34, n.1, p.78-82, 2000.

BETTIOL, W.; KIMATI, H. Efeito de Bacillus subtilis sobre Pyricularia oryzae agente causal da brusone do arroz. Pesquisa Agropecuária Brasileira, Brasília, v.25, n.8, p.1165-1174, 1990. BETTIOL, W.; TRATCH, R.; GALVÃO, J.A.H. Controle de doenças de plantas com biofertilizantes. Jaguariúna: EMBRAPACNPMA, 1997. 22 p. (EMBRAPA-CNPMA. Circular Técnica, 02).

CARMO, M.G.F.; MACAGNAN, D.; CARVALHO, A.O. Progresso da mancha-bacteriana do pimentão a partir de diferentes níveis iniciais de inóculo e do emprego ou não do controle com oxicloreto de cobre. Horticultura Brasileira, Brasília, v.19, n.3, p.342-347, 2001.

CASTRO, C.M.; SANTOS, A.C.V.; AKIBA, F. Comprovação in vitro da ação inibidora do biofertilizante "Vairo" produzido a partir da fermentação anaeróbica do esterco bovino, sobre germinação de conídios de diversos gêneros de fungos fitopatogênicos. In: REUNIÃO BASILEIRA SOBRE CONTROLE BIOLÓGICO DE DOENÇAS EM PLANTAS, 4., 1991, Campinas. Anais... Jaguariúma: EMBRAPA-CNPDA, 1991. p.18.

DELEITO, C.S.R. O biofertilizante Agrobio: composição microbiana e efeito sobre a mancha bacteriana do pimentão. 2002.95 f. (Tese mestrado), UFRRJ, Seropédica.
FAHY, P.C.; HAYWARD, A.C. Media and methods for isolation and diagnostic test. In: FAHY, P.C. \& PERSLEY, G.J. (Eds.) Plant bacterial disease: a diagnostic guide. Sidney: Academic Press, 1983. cap.16, p. 337-338.

FERNANDES, M.C.A. O biofertilizante Agrobio. Informativo do Centro Nacional de Pesquisa de Agrobiologia, n. 13. EMBRAPA-Agrobiologia, Seropédica, Ano 4, setembro de 2000. In: A Lavoura, v.103, n.634, p.42-43, 2000.

JONES, J.B.; LACY, G.H.; BOUZAR, H.; STALL, R.E.; SCHAAD, N.W. Reclassification of the Xanthomonads associated with bacterial spot disease of tomato pepper. Systematic and Applied Microbiology, v.27, n.6, p.755-762, 2004. JONES, J.B.; WOLTZ, S.S.; JONES, J.P.; PORTIER, K.L. Population dynamics of Xanthomonas campestris pv. vesicatoria on tomato leaflets treated with copper bactericides. Phytopathology, v.81, n.7, p. 714-719, 1991.

MARCO, G.M.; STALL, R.E. Control of bacterial spot of pepper initiated by Xanthomonas campestris pv. vesicatoria that differ in sensibility to copper. Plant Disease, v.67, n.7, p.779-781, 1983.

QUEZADO-DUVAL, A.M.; GAZZOTO FILHO, A.; LEITE JÚNIOR, R.P.; CAMARGO, L.E.A. Sensibilidade ao cobre, estreptomicina e oxitetraciclina em Xanthomonas spp. associadas à mancha-bacteriana do tomate para processamento industrial. Horticultura Brasileira, Brasília, v.21, n.4, p.670-675, 2003.

SALGADO, L.A.S.; CARMO, M.G.F.; VIEGAS, E.C.; TEIXEIRA, D.E.; BARRETO, A.S.; PIZARRO, A.P.B.; GILBERT. B. Evaluation of antimicrobial activity of extracts of medicinal plants on three tomato phytopathogens. Acta Horticulturae, n.579, p.87-90, 2002.

TRATCH, R.; BETTIOL, W. Efeito de biofertilizantes sobre o crescimento micelial e a germinação de esporos de alguns fungos fitopatogênicos. Pesquisa Agropecuária Brasileira, Brasília, v.32, n.11, p.1131-1139, 1997.

WARD, H.P.; O' GARRO, L.W. Bacterial spot of pepper and tomato in Barbados. Plant Disease, v.76, n.10, p.1046-1048, 1992. 